\title{
A SÉRIE NORTE-AMERICANA 13 REASONS WHY, A REALIDADE BRASILEIRA E A VIOLAÇÃO DE DIREITOS FUNDAMENTAIS: PRECISAMOS FALAR SOBRE (CYBER)BULLYING
}

\section{Patrícia Adriani Hoch ${ }^{1}$}

RESUMO: A prática de violência é comum com a ocorrência de bullying e cyberbullying. Em virtude dessas práticas no Brasil e da realidade retratada na série 13 reasons why, o presente estudo busca analisar a violação de direitos fundamentais, bem como a possibilidade de responsabilização civil. Para tanto, realiza-se abordagem dedutiva quanto à compreensão dos fenômenos e a comparação entre as situações evidenciadas na série e a realidade brasileira. Conclui-se que o Brasil também apresenta casos de prática de violência, o que, além da responsabilização dos envolvidos e da escola, evidencia a necessidade de prevenção.

Palavras-Chave: bullying; cyberbullying; 13 reasons why; violência; direitos fundamentais.

\section{THE NORTH AMERICAN SERIES 13 REASONS WHY, THE BRAZILIAN REALITY AND THE VIOLATION OF FUNDAMENTAL RIGHTS: WE NEED TO TALK ABOUT (CYBER) BULLYING}

\begin{abstract}
The practice of violence is common with the occurrence of bullying and cyberbullying. Due the practices in Brazil and the reality there are 13 reasons why, the present study has scope the analysis the violation of fundamental rights, as well as a possibility of civil responsibility. Therefore, an deductive approach to comprehension the phenomena and a comparative procedure between the situations evidenced in the series 13 reasons why and the Brazilian reality. The conclusion is that Brazil presents cases of violence, which, in addition to the accountability of those involved and the school, shows the need to prevent.
\end{abstract}

Keywords: bullying; cyberbullying; 13 reasons why; violence; fundamental rights.

\footnotetext{
${ }^{1}$ Mestre em Direito pelo Programa de Pós-Graduação em Direito da Universidade Federal de Santa Maria (UFSM), Área de concentração: Direitos Emergentes da Sociedade Global, Linha de Pesquisa: Direitos na Sociedade em Rede. Pós-Graduada em Direito Processual Tributário. Professora do Curso de Direito da UFSM. Coordenadora do Núcleo Jurisdição Constitucional e Direitos Fundamentais (NUJUDI) da UFSM. Advogada. E-mail: patricia.adriani@hotmail.com.
} 


\section{INTRODUÇÃO}

Diariamente são veiculadas pela mídia notícias acerca de pessoas que sofreram bullying na escola ou cyberbullying (bullying na Internet). Esse tema é evidenciado na série americana intitulada 13 (thirteen) reasons why (os treze porquês), produzida pela Netflix e disponibilizada em 31 de março de 2017.

A referida série baseia-se no romance Thirteen Reasons Why, escrito por Jay Asher e sua grande repercussão está relacionada à demonstração da ocorrência de casos de bullying e cyberbullying, bem como por culminar no suicídio da personagem principal, Hannah Baker. A partir do imenso e global destaque da série nas mídias tracionais e eletrônicas, entre especialistas, adolescentes e adultos, verifica-se a urgência em colocar esse fenômeno na pauta do debate e dos estudos científicos e jurídicos.

Isso, pois, diariamente pessoas, especialmente crianças e adolescentes, sofrem as graves consequências do bullying e do cyberbulling, sendo que, muitas vezes, as agressões e o sofrimento da vítima permanecem velados até que ocorra uma tragédia, como no caso da série e em muitos que ocorrem diariamente e são noticiados pela mídia.

Sabe-se que as brincadeiras acontecem cotidianamente, de maneira normal e espontânea entre jovens, há muito tempo, sobretudo durante a fase de desenvolvimento e socialização, dentro e fora da escola. Essa prática também é comum e se estende para o âmbito virtual, no qual ocorre a comunicação e interação entre pessoas, especialmente mediante a utilização de redes sociais, a exemplo do Facebook, do Instagram e do Twitter.

Contudo, as brincadeiras nem sempre são saudáveis e divertidas para todos os envolvidos. Sendo assim, quando refletem atos de violência física e moral que fogem à normalidade, coadunando em um desequilíbrio de poder, de maneira repetitiva, é importante que a escola, a família e a sociedade adotem as medidas cabíveis para a solução do conflito.

O bullying ocorre, sobretudo, na escola, eis que esta é um importante instrumento de inclusão social, na qual o indivíduo vive e convive desde muito cedo. Ela representa um dos primeiros contatos da pessoa com o ambiente público sendo, portanto, influenciadora direta na formação de valores e caráter, bem como no desenvolvimento das potencialidades intelectuais, afetivas e sociais dos estudantes.

Porém, diante da expansão do uso das tecnologias de informação e de comunicação (TIC), o bullying ocorre de forma cada vez mais intensificada, vem sendo praticado também no 
âmbito virtual, especialmente na Internet. Neste ambiente, a violência é denominada cyberbullying, uma vez que é praticada no ciberespaço (LÉVY, 1999, p. 17)².

Deste modo, é necessário prevenir e coibir qualquer ofensa ou dano decorrente do convívio entre alunos, jovens e internautas, de forma a combater condutas agressivas e violentas, sobretudo excessivas, conhecidas como bullying e cyberbullying. O objetivo da prevenção é o de evitar que a violência (física ou verbal) afete o processo pedagógico de ensino e aprendizagem e cause consequências ainda mais devastadoras, como o isolamento e o sofrimento solitário.

Por tais razões, essa temática merece atenção no âmbito científico e acadêmico, eis que, inclusive, se trata de uma verdadeira violação de direitos fundamentais, tais como a honra, imagem e, fundamentalmente, a dignidade da pessoa humana. Devido à sua gravidade e abrangência, atualmente, o fenômeno não é mais somente considerado exclusivo da área educacional e sim um problema de saúde pública.

Tanto é verdade que nos últimos anos vêm sendo criadas diversas leis estaduais e municipais, bem como projetos de lei nacionais, com o intuito de prevenir e combater o bullying e o cyberbullying, conscientizando a sociedade como um todo acerca da importância da temática e da prevenção da violência.

Tendo em vista a relevância, em 2015 foi criado o Programa de Combate à Intimidação Sistemática (bullying), em todo o Território Nacional, por meio da Lei $\mathrm{n}^{\circ}$ 13.185, de 06 de novembro de 2015 (BRASIL, 2015). Essa novel legislação representa um importante instrumento normativo para o combate a todo e qualquer tipo de agressão, seja física ou psicológica.

Além disso, o texto constitucional estabelece que a escola, a família e a sociedade devam combater a ocorrência dessas violências de forma conjunta. Para tanto, o presente artigo possui o objetivo de compreender as nuances relacionadas ao bullying e ao cyberbullying no Brasil e na série 13 reasons why, bem como refletir acerca da proteção constitucional de direitos fundamentais que são violados nesses casos de violência e da possibilidade de responsabilidade civil do(s) agressor(es) e da escola.

\footnotetext{
${ }^{2}$ Conforme explica Lévy (1999, p. 17), "o ciberespaço (que também chamarei de rede) é o novo meio de comunicação que surge da interconexão mundial de computadores. $O$ termo especifica não apenas a infraestrutura material da comunicação digital, mas também o universo oceânico de informações que ela abriga, assim como os seres humanos que navegam e alimentam esse universo".
} 
A partir disso, por meio do método de abordagem dedutivo e do método de procedimento comparativo, o estudo busca a reflexão sobre o tema do bullying e cyberbullying, aliado à violação de direitos fundamentais, e sobre a responsabilização na esfera cível, a fim de contribuir na disseminação de conhecimento e incentivar o enfrentamento da violência no Brasil.

Para a fluidez da compreensão, o presente artigo foi dividido em três partes. A primeira destina-se à compreensão das interfaces do bullying e do cyberbullying mediante esclarecimentos acerca desses fenômenos, com dados estatísticos sobre a realidade Brasileira e análise da série norte-americana 13 reasons why. Na segunda, aborda-se a violação de direitos fundamentais em decorrência da prática de bullying e de cyberbullying, discutindo-se a possibilidade de responsabilização civil, bem como a necessidade de prevenção, a fim de desestimular a violência.

\section{COMPREENDENDO OS FENÔMENOS: AS INTERFACES DO BULLYING E DO CYBERBULLYING NO BRASIL E NA SÉRIE NORTE-AMERICANA 13 REASONS WHY}

O bullying é uma expressão inglesa, derivada do verbo to bully, que significa tratar de forma grosseira, desumana, reservando-se o termo bully, para fazer referência a uma pessoa grosseira, autoritária que ataca os mais fracos (HIRIGOYEN, 2002).

Caracteriza-se como bullying todo tipo de comportamento agressivo, intencional e repetitivo inerente às relações interpessoais, tais como: ofender, zoar, gozar, encarnar, sacanear, humilhar, discriminar, excluir, isolar, ignorar, intimidar, perseguir, assediar, aterrorizar, amedrontar, tiranizar, dominar, bater, chutar, empurrar, ferir, roubar e quebrar pertences.

Para Fante (2005, p. 28-29) o bullying escolar pode ser entendido como:

\footnotetext{
[..] um conjunto de atitudes agressivas, intencionais e repetitivas que ocorrem sem motivação evidente, adotado por um ou mais alunos contra outro(s), causando dor, angústia e sofrimento. Insultos, intimidações, apelidos cruéis, gozações que magoam profundamente, acusações injustas, atuações em grupo que hostilizam, ridicularizam e infernizam a vida de outros alunos, levando-os à exclusão, além de dados físicos, morais e materiais, são algumas das manifestações do comportamento bullying.
}

A autora também explica quais são os protagonistas desse fenômeno, quais sejam: a) vítima típica: normalmente apresenta aspecto físico de sensibilidade, timidez, passividade, submissão, insegurança, baixa auto-estima, dificuldade de aprendizagem, ansiedade, aspecto 
depressivo e coordenação motora deficiente; b) vítima provocadora: que provoca reações que não possui habilidades para lidar; c) vítima agressora: que reproduz os maus-tratos sofridos; d) agressor: que vitimiza os mais fracos e, por fim, e) espectador: que presencia os maus-tratos (FANTE, 2005, p. 28-29).

Conforme a Cartilha intitulada "Projeto Justiça nas Escolas" (BRASIL, 2010), realizado pelo Conselho Nacional de Justiça, o bullying se manifesta de várias formas. A verbal constitui xingamentos, insultos, insinuações e uso de apelidos. A moral revela uma lesão à honra da vítima, por difamação, discriminação do sexo, idade, opção sexual, deficiência física, doença. Já a psicológica se revela por perseguições, intimidações, chantagem e ameaças em geral. A física, por sua vez, se dá por meio de empurrões, socos, chutes. A forma material ocorre quando há furto de material e pertences.

Por fim, existe uma maneira mais recente de intimidação, conhecida como cyberbullying, a qual é exercida virtualmente (no ciberespaço), por meio do uso de tecnologias de informação e de comunicação (TIC), tais como celular, e-mail, redes sociais na Internet, entre outros. A violência, nestes casos, ocorre mediante a utilização de redes sociais, a exemplo do Facebook, do Instagram e do Twitter.

Nessa perspectiva, Constantini (2004) ressalta que nem toda a agressão ou conflito que ocorre entre estudantes são considerados como bullying e sim somente aqueles comportamentos repetitivos de intimidação, ameaça e violência física ou psíquica impostos a indivíduos vulneráveis que não conseguem se defender, os quais ficam em uma condição de sujeição, isolamento, sofrimento e marginalização.

Assim, ao contrário do que o senso comum muitas vezes acredita, o bullying somente é caracterizado quando há um desequilíbrio de forças (e não em qualquer caso em que ocorra alguma brincadeira ofensiva ou agressiva). Isso pode ser facilmente verificado quando se analisam quais são os critérios adotados pelos agressores para a escolha da vítima.

Barbosa (2010) explica que, normalmente, as vítimas apresentam alguma característica ou atitude que as destoam do grupo, como, por exemplo, a timidez, introspecção, credo, raça ou orientação sexual diferenciada, ou quando são consideradas "nerds", muito magras, entre outros.

$\mathrm{Na}$ realidade, nem sempre há uma justificativa provável para a escolha, mas a motivação do bullying é o referido desequilíbrio existente entre o bullie e o ofendido. Diante dessa conjuntura, Fante (2005, p. 28) acrescenta: 
O desequilíbrio de poder caracteriza-se pelo fato de que a vítima não consegue se defender, devido a inúmeros fatores: por ser de menor estatura ou força física; por estar em minoria; por apresentar pouca habilidade de defesa; por falta de assertividade e pouca flexibilidade psicológica perante o autor ou autores dos ataques.

Ao contextualizar o fenômeno, Guareschi et. al. (2008) salienta que a discriminação é um dos fatores que podem dar origem ao bullying, revelando-se como uma intolerância à diferença das homogeneizações e padrões estabelecidos pela sociedade em geral. Por esse motivo, aquele que é considerado uma pessoa normal tem a falsa ideia de superioridade, o que leva à aversão ao diferente.

Nesse sentido, a sociedade, começando no ambiente escolar (tanto na fase de iniciação, como nos ensinos fundamental e médio), reprime comportamentos diferenciados do estigma e tenciona a simplesmente excluir o indivíduo, o que culmina em preconceito. $\mathrm{O}$ problema primordial nessa situação, principalmente quando envolve crianças e adolescentes, são as consequências, que podem perdurar ao longo do tempo e atingir dimensões sociais e intelectuais na vítima.

Para Carvalho (2006) alunos isolados são geralmente introspectivos, tímidos, reservados e pouco participativos, motivo pelo qual geralmente são considerados alunos disciplinados, por não causarem nenhuma perturbação, fato que contribui para que o professor não perceba em sala de aula seu isolamento ou exclusão, em caso de bullying.

Ainda com ênfase na perspectiva da desigualdade, Beane (2010) ressalta que as causas do bullying decorrem da necessidade de dominação, exercício de poder e controle por parte do agressor em relação à vítima, a fim de se destacar perante os demais, ou a exteriorização de problemas familiares e da forma de tratamento com a qual é acostumado em casa.

Fante (2005) explica que, nesses casos, usualmente, os pais do agressor deixam de supervisioná-lo de maneira adequada e se comportam de maneira agressiva ao solucionar conflitos. E é por meio da violência que o bullie busca afirmação e reconhecimento dos demais, como aquela pessoa que exerce uma espécie de poder sobre os mais fracos.

O bullying é uma das formas de violência que ocorre diariamente nas escolas, conforme foi constatado na "Pesquisa Nacional de Saúde do Escolar de 2015" (BRASIL, 2016), realizada pelo Instituto Brasileiro de Geografia e Estatística (IBGE), em parceria com o Ministério da Saúde e apoio do Ministério da Educação, junto aos estudantes matriculados e frequentando escolas de ensino regular devidamente cadastradas no Censo Escolar e que possuam turmas nas etapas de interesse. 
Segundo a pesquisa, foram realizadas duas amostras: a primeira com alunos do $9^{\circ}$ ano do ensino fundamental e a segunda com alunos do $6^{\circ}$ ao $9^{\circ}$ ano do ensino fundamental e da $1^{\mathrm{a}}$ a $3^{\text {a }}$ série do ensino médio (BRASIL, 2016, p. 71). Os alunos entrevistados responderam ter sofrido bullying, conforme se depreende dos resultados do referido estudo:

De acordo com os resultados da pesquisa, a pergunta sobre a frequência com que os colegas de escola os trataram bem ou foram prestativos nos 30 dias anteriores à pesquisa, os resultados mostraram que $61,9 \%$ dos estudantes brasileiros responderam que foram bem-tratados pelos colegas na maior parte do tempo ou sempre. Cerca de $64,9 \%$ das meninas declararam ter sido bem tratadas pelos colegas, enquanto que entre os meninos esse percentual foi de 58,7\% (Tabela de Resultados 1.1.9.6).

Questionados sobre a frequência com que os colegas da escola esculacharam, zoaram, mangaram, intimidaram ou caçoaram tanto que o aluno ficou magoado, incomodado, aborrecido, ofendido ou humilhado nos 30 dias anteriores à pesquisa, 7,4\% dos escolares brasileiros afirmaram que na maior parte do tempo ou sempre se sentiram humilhados por provocações. Os percentuais foram próximos para os estudantes do sexo masculino $(7,6 \%)$ e feminino $(7,2 \%)$, como é demonstrado no Gráfico 15 . Entre os alunos das escolas públicas, o percentual foi de $7,6 \%$ e entre os das escolas privadas, 6,5\%. Dos escolares entrevistados, 53,4\% responderam nenhuma vez, e $39,2 \%$, raramente ou às vezes se sentiram humilhados por provocações feitas pelos colegas de escola nos 30 dias anteriores à pesquisa. A Região Sudeste apresentou o maior percentual $(8,3 \%)$ de escolares que declararam sofrer constrangimento ou humilhação na maior parte do tempo ou sempre. O Estado de São Paulo $(9,0 \%)$ foi o estado com maior percentual (Tabela de Resultados 1.1.9.7).

Quando perguntados se o escolar já havia esculachado, zombado, mangado, intimidado ou caçoado algum de seus colegas de escola nos 30 dias anteriores à pesquisa, 19,8\% responderam que sim. Dentre os meninos, esse percentual foi de $24,2 \%$ e entre as meninas, $15,6 \%$. Percentual maior entre os alunos de escolas privadas $(21,2 \%)$ do que entre as escolas públicas (19,5\%). A Região Sudeste apresentou o maior percentual $(22,2 \%)$, assim como o Estado de São Paulo $(24,2 \%)$ (Tabela de Resultados 1.1.9.9). Dentre os que se sentiram humilhados pelas provocações dos colegas, responderam como principais motivos, a aparência do corpo $(15,6 \%)$ e aparência do rosto (10,9\%) (BRASIL, 2016, p. 71).

O gráfico abaixo (IBGE, 2015) demonstra os percentuais referentes à violência, segurança e acidentes dos alunos do $9^{\circ}$ ano do ensino fundamental, que revelam que $7,2 \%$ do público feminino e que 7,6\% do público masculino sofreu bullying nos 30 dias anteriores à pesquisa. 


\section{Amostra 1: Violências, Segurança e Acidentes By IBGE}

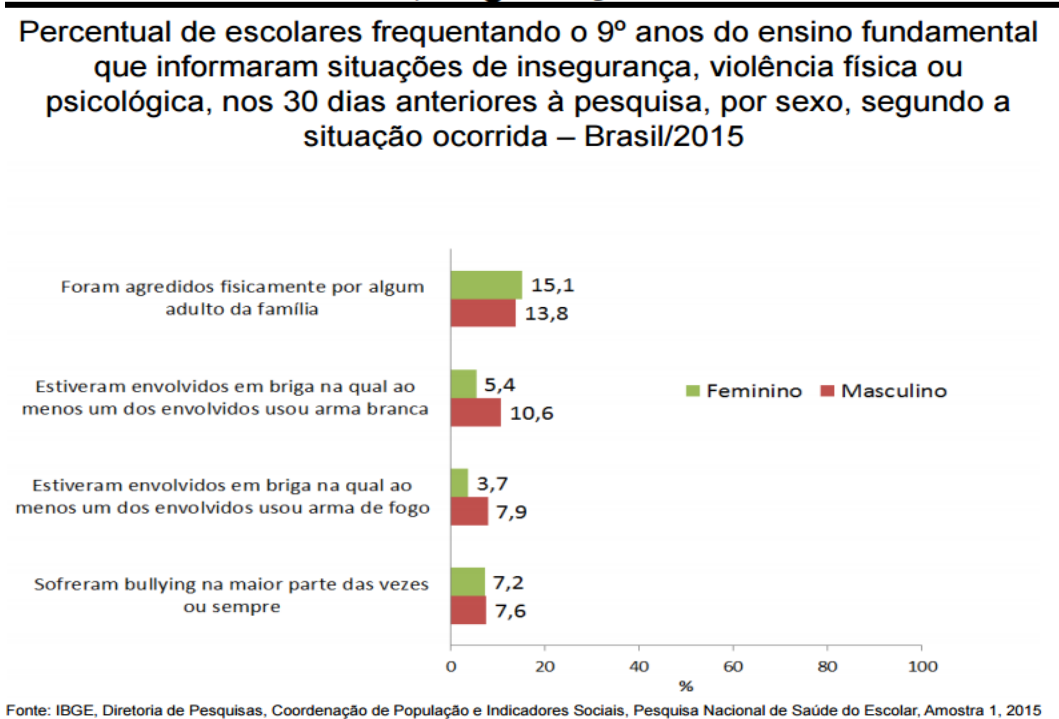

Esses dados revelam que a realidade brasileira apresenta casos de bullying, o qual normalmente é estendido também para o âmbito virtual (cyberbullying). Do mesmo modo, na série norte-americana intitulada 13 reasons why, que possui o bullying e o cyberbullying inseridos nas temáticas centrais, verifica-se que, em diversas situações, principalmente na escola, alunos que se destacam no contexto escolar agridem colegas, a fim de demonstrar seu poder ou superioridade.

Shariff (2011) explica que o favorecimento do agressor em razão do desequilíbrio de poder, o estímulo dos espectadores que, inclusive, não ajudam a vítima, o isolamento dos ofendidos fortalecendo o poder do bullie, são fatores gerais que contribuem para a prática de bullying.

Ademais, o envio de fotografias lesivas à intimidade de determinado aluno ocorre por aparelhos celulares, demonstrando a ocorrência do cyberbullying, situação que também restou evidenciada na série em comento.

Ocorre que, como esclarece Fante (2005), as consequências dessa violência, física ou psicológica, para as vítimas são graves, pois estas perdem o interesse pela escola, apresentam déficit de concentração e aprendizagem, queda do rendimento, absentismo, ocorrendo também, em algumas situações, a evasão escolar.

Diante desse contexto, o próximo tópico visa abordar a violação de direitos fundamentais em razão da violência, que ocorre nos ambientes off-line e on-line, bem como a possibilidade de responsabilização cível do(s) agressor(es) e das escolas. 


\section{A VIOLAÇÃO DE DIREITOS FUNDAMENTAIS EM DECORRÊNCIA DA} PRÁTICA DE BULlying E DE CYBERBUllying: A POSSIBILIDADE DE RESPONSABILIZAÇÃO CIVIL E A NECESSIDADE DE PREVENÇÃO

As interfaces do bullying e do cyberbullying mencionadas no tópico anterior nos remetem à constatação de que a concretização desses fenômenos lesa direitos fundamentais das vítimas, consagrados no texto constitucional.

O bullying - por ser uma prática repetitiva de vitimização do mais fraco por meio de um desequilíbrio de poder (FANTE, 2005; BARBOSA, 2010; GUARESCHI et. al., 2008) fere a dignidade da pessoa humana, fundamento primário de todo ordenamento jurídico brasileiro. Isso porque atinge a integridade física e psíquica da vítima, gerando consequências extremamente graves.

Ferraz (1991, p. 19) salienta que a dignidade da pessoa humana:

[..] é base da própria existência do Estado brasileiro e, ao mesmo tempo, fim permanente de todas as suas atividades. É a criação e manutenção das condições para que as pessoas sejam respeitadas, resguardadas e tuteladas, em sua integridade física e moral, asseguradas o desenvolvimento e a possibilidade da plena concretização de suas potencialidades e aptidões.

Nesse diapasão, esse princípio se revela como uma proteção à integridade e intimidade do indivíduo, a fim de que todos sejam respeitados e tratados, sobretudo, de maneira digna, sob pena de indenização, em caso de violação. Essa ideia é salvaguardada no artigo $5^{\circ}$, X, da Constituição Federal brasileira, ao estabelecer que "são invioláveis a intimidade, a vida privada, a honra e a imagem das pessoas, assegurado o direito a indenização pelo dano material ou moral decorrente de sua violação".

Esse fundamento é categórico em relação à criança e ao adolescente, no artigo $227^{3}$ da Constituição Federal. Por sua vez, o Estatuto da Criança e do Adolescente (ECA) também abordou a questão da dignidade, estabelecendo em seu artigo 18 que "é dever de todos velar pela dignidade da criança e do adolescente, pondo-os a salvo de qualquer tratamento desumano, violento, aterrorizante, vexatório ou constrangedor”.

\footnotetext{
3 “Art. 227 - É dever da família, da sociedade e do Estado assegurar à criança, ao adolescente e ao jovem, com absoluta prioridade, o direito à vida, ao lazer, à profissionalização, à cultura, à dignidade, ao respeito, à liberdade e à convivência familiar e comunitária, além de colocá-los a salvo de toda forma de negligência, discriminação, exploração, violência, crueldade e opressão".
} 
Como se percebe, a tutela da dignidade é finalidade precípua do Estado Brasileiro, sendo que sua violação por meio da prática de bullying e cyberbullying revela-se como um ato ilícito, eis que consiste na intenção de desestabilizar psicologicamente o ofendido, o qual resulta em abalo acima do razoável.

Tais situações, do ponto de vista normativo, geram, inclusive, a responsabilidade civil. O jurista Cavalieri Filho (2010) define o ato ilícito como lesão culposa e ilegal às regras sociais que devem ser respeitadas por todos sendo, portanto, uma fonte de obrigação de indenizar. Significa dizer que há uma lesão a um dever jurídico preexistente.

Essa posição é adotada pelo Código Civil brasileiro no artigo 186, segundo o qual "aquele que, por ação ou omissão voluntária, negligência ou imprudência, violar direito e causar dano a outrem, ainda que exclusivamente moral, comete ato ilícito". O artigo 187, do mesmo diploma legal, determina que "também comete ato ilícito o titular de um direito que, ao exercêlo, excede manifestamente os limites impostos pelo seu fim econômico ou social, pela boa-fé ou pelos bons costumes".

Importante salientar que, de acordo com a Constituição Federal, que está no topo normativo de nosso ordenamento jurídico, a manifestação do pensamento é livre, considerando o direito à liberdade de expressão. Contudo, quando ultrapassa os limites legais e atinge os direitos da personalidade do indivíduo, configura-se como abuso de direito.

Cavalieri Filho (2010) esclarece que a finalidade do abuso de direito consiste em evitar que o titular de um direito desvie a finalidade de seu poder. Quando isso ocorre, o ato possui formalidade legal, contudo, é ilícito em decorrência da colisão com os valores axiológicos da legislação.

Com efeito, essa observância aos direitos fundamentais pela liberdade de expressão foi ressaltada pelo Ministro Carlos Ayres Britto, no julgamento da ADPF no 130, em 21 de fevereiro de 2008:

[...] o livre exercício das liberdades de pensamento, criação, expressão e informação pressupõe a observância às garantias fundamentais da vedação ao anonimato, do direito da resposta, do direito à indenização por danos materiais ou morais, à intimidade, à vida privada, à honra, à imagem das pessoas; o livre exercício de qualquer trabalho, ofício ou profissão, bem como o direito ao resguardo do sigilo da fonte de informação (BRASIL, 2008). 
Sendo assim, superada a constatação da ilicitude do ato, a legislação estabelece como consequência imediata a necessidade de indenização, com base no artigo $927^{4}$ do Código Civil. Isso se deve ao fato de que a legislação possui o escopo de punir aquele que contrariar um dever legal de não violar direitos de outrem, lhe causando danos, seja de natureza moral ou material.

É o que ocorre nos casos de bullying e cyberbullying, tendo em vista que esses tipos de violência causam prejuízos imensos à(s) vítima(s), em razão do sofrimento decorrente da lesão à dignidade e à personalidade, diretamente relacionadas à sua reputação, honra, imagem, amor-próprio, bem como integridade física e psíquica.

Diante disso, embora não de forma específica, o ordenamento jurídico brasileiro já previa a necessidade de reparação da ilicitude causa pela violência (em sentido amplo), por meio da obrigação de indenizar.

De forma específica, em 2015, foi promulgado um importante marco regulatório, através do qual foi instituído o Programa de Combate à Intimidação Sistemática (bullying), em todo o Território Nacional, por meio da Lei n ${ }^{\circ}$ 13.185, de 06 de novembro de 2015 (BRASIL, 2015). Essa foi a primeira lei brasileira que possui como escopo prevenir e combater a prática da intimidação sistemática no País, sendo considerada um marco jurídico de combate ao bullying.

Segundo o governo federal, caracteriza-se a intimidação sistemática (bullying) quando há violência física ou psicológica em atos de intimidação, humilhação ou discriminação e, ainda, a intimidação sistemática na rede mundial de computadores (cyberbullying), para depreciar, incitar a violência, adulterar fotos e dados pessoais com o intuito de criar meios de constrangimento psicossocial (BRASIL, 2015).

Para além da responsabilização do(s) agressor(es), os índices de violência, como demonstrado na "Pesquisa Nacional de Saúde do Escolar de 2015" (BRASIL, 2016), demonstram a necessidade de que se (re)avalie qual é o papel e a responsabilidade das escolas, tanto públicas, como privadas, perante a ocorrência de violência, especialmente quando se trata de casos de bullying e cyberbullying.

Segundo Baruffi (2008) a escola possui papel fundamental no que tange a inserção e socialização do indivíduo, bem como a construção da cidadania. $\mathrm{O}$ autor salienta, ainda, que a educação é um direito coletivo e que, portanto, não deve sofrer qualquer tipo discriminação.

\footnotetext{
4 “Art. 927. Aquele que, por ato ilícito (arts. 186 e 187), causar dano a outrem, fica obrigado a repará-lo”.
} 
Sob esse ponto de vista, a própria Constituição Federal assegura em seu artigo $205^{5} \mathrm{o}$ direito à educação a todos os indivíduos, o que deve ser garantido pela sociedade como um todo, independente da existência de diferenças. Especificamente quanto à violência escolar, para Pereira (2002, p.11):

\begin{abstract}
A educação e a cultura deveriam tender a eliminar as formas agressivas de resolução de tensões que provocam as diferenças individuais. A educação deveria valorizar e promover os comportamentos de empatia, a negociação verbal, o intercambio de idéias, a cedência de ambas as partes na procura da justiça, no direito à igualdade de oportunidades para todos e no direito às diferenças de cada um. Educar para a liberdade com igualdade de direitos e obrigações, em que os direitos de um determinam onde começam os direitos dos outros.
\end{abstract}

Diante disso, Stoco (1999, p. 32) ensina que a escola possui o seguinte dever de zelar pela integridade física do aluno, prevenindo ofensas que prejudique, o convívio escolar:

\begin{abstract}
Ao receber o estudante menor, confiado ao estabelecimento de ensino da rede oficial ou da rede particular para as atividades curriculares, de recreação, aprendizado e formação escolar, a entidade de fica investida do dever de guarda e de preservação da integridade física do aluno, com a obrigação de empregar a mais diligente vigilância, para prevenir e evitar qualquer ofensa ou dano aos seus pupilos, que possam resultar do convívio escolar.
\end{abstract}

Consequentemente, o próprio autor salienta que a escola deverá reparar danos que porventura venham a existir se o aluno sofrer algum tipo de violência enquanto permanecer no estabelecimento.

Nesse ponto, é importante que se faça uma distinção entre as escolas de diferentes naturezas. As públicas atuam sob responsabilidade do Poder Público, sendo, portanto, acionados judicialmente em caso de bullying, o Município, Estado e/ou União. Já as privadas, além de integrar diretamente o polo passivo de uma ação judicial, a elas se aplica o Código de Defesa do Consumidor, em virtude da existência de relação de consumo diante da prestação de serviços, o que traz diversas implicações jurídicas específicas acerca do dano moral e a indenização.

Marques (2003, p. 248) explica que "a responsabilidade imposta pelo art. 14 do CDC é objetiva, independe de culpa e com base no defeito, dano e nexo causal entre o dano ao

\footnotetext{
5 “Art. 205. A educação, direito de todos e dever do Estado e da família, será promovida e incentivada com a colaboração da sociedade, visando ao pleno desenvolvimento da pessoa, seu preparo para o exercício da cidadania e sua qualificação para o trabalho".
}

Rev. de Direito, Governança e Novas Tecnologias | e-ISSN: 2526-0049 | Porto Alegre | v. 4 | n. 2 | p. 44 - 60 | Jul/Dez. 2018 
consumidor-vítima (art. 17) e o defeito do serviço prestado no mercado brasileiro". Além disso, em razão da onerosidade, também podem ser aplicados aos estabelecimentos privados a responsabilidade pela reparação civil de que tratam os artigoa 932, IV e 933 do Código Civil.

No que concerne especialmente às escolas públicas, a Administração Pública é responsável pelos danos considerando o princípio a teoria do risco consagrado no artigo $37, \S$ $6^{\circ}$ da Constituição Federal.

Cahali (1995) esclarece que ao desempenhar sua função social, o Estado assume a responsabilidade por danos em casos de omissão de guarda, fiscalização e vigilância em suas dependências. Na mesma linha, elucida Meirelles (2006, p. 654):

\begin{abstract}
[...] incide a responsabilidade civil objetiva quando a Administração Pública assume o compromisso de velar pela integridade física da pessoa e esta vem a sofrer um dano decorrente da omissão do agente público naquela vigilância. Assim, alunos da rede oficial de ensino, pessoas internadas em hospitais públicos ou detentos, caso sofram algum dano quando estejam sob a guarda imediata do Poder Público, têm direito à indenização, salvo se ficar comprovada a ocorrência de alguma causa excludente daquela responsabilidade estatal.
\end{abstract}

Independente da natureza da escola (pública ou privada), a cartilha lançada pelo Conselho Nacional de Justiça (BRASIL, 2010) orienta que os responsáveis pelos estabelecimentos de ensino acionem os pais dos atores envolvidos, os Conselhos Tutelares, bem como os órgãos de proteção à criança e ao adolescente. Caso essa obrigatoriedade, estabelecida no artigo $13^{6}$ do ECA, não seja cumprida, será aplicada a multa de que trata o artigo $245^{7}$, do Estatuto

Também é importante que as escolas e a sociedade como um todo se preocupem com a prevenção da violência, evitando que surjam problemas mais graves, com base no artigo 70 do estatuto, que estabelece ser "dever de todos prevenir a ocorrência de ameaça ou violação dos direitos da criança e do adolescente".

Na série norte-americana 13 reasons why percebe-se que, após o suicídio de Hannah (personagem principal), em consequência do bullying e do cyberbulling sofridos por agressões

\footnotetext{
6 "Art. 13. Os casos de suspeita ou confirmação de maus tratos contra criança ou adolescente serão obrigatoriamente comunicados ao Conselho Tutelar da respectiva localidade, sem prejuízo de outras providências legais".

7 “Art. 245. Deixar o médico, professor ou responsável por estabelecimento de atenção à saúde e de ensino fundamental, pré-escola ou creche, de comunicar à autoridade competente os casos de que tenha conhecimento, envolvendo suspeita ou confirmação de maus-tratos contra criança ou adolescente: Pena multa de três a vinte salários de referência, aplicando-se o dobro em caso de reincidência".
}

Rev. de Direito, Governança e Novas Tecnologias | e-ISSN: 2526-0049 | Porto Alegre | v. 4 | n. 2 | p. 44 - 60 | Jul/Dez. 2018 
diversas de vários colegas de escola, os personagens (alunos e colegas) envolvidos e o funcionário da escola (que ouviu relatos de Hannah acerca da violência) permanecem em dúvida sobre denunciar, ou não, os fatos ocorridos.

Todavia, a própria série evidencia que se os envolvidos (como as testemunhas das agressões, por exemplo) tivessem se manifestado antes perante seus pais, autoridades ou diretor da escola, a perpetuação da violação de direitos fundamentais de Hannah e seu suicídio poderiam ter sido evitados.

Esses fatos abordados na série retratam a realidade enfrentada, especialmente, por jovens e crianças, dentro e fora da escola, on-line e off-line, de modo que é possível perceber que a realidade brasileira não é diferente. A mídia diariamente expõe casos de violação de direitos através de bullying e cyberbullying e das graves consequências decorrentes da violência.

Dito isto, a responsabilização é importante, sendo necessário que as pessoas envolvidas em casos de violência denunciem o(s) agressor(es), a fim de que a punição com o pagamento de indenização para a(s) vítima(s) seja uma forma de desestímulo para essas prática.

A partir dessas considerações, extrai-se que a violação de direitos fundamentais em decorrência da prática de bullying e cyberbullying é passível de responsabilização civil. Ademais, a denúncia de casos envolvendo esses dois tipos de violência é fundamental para que se evitem consequências mais graves, sendo a prevenção uma importante medida no combate ao bullying e cyberbullying, o que acabou não ocorrendo na série 13 reasons why, culminando no suicídio da personagem vitimada pelos colegas.

\section{CONSIDERAÇÕES FINAIS}

A realização deste estudo proporcionou o enfrentamento de uma temática de extrema importância, especialmente no contexto escolar, que muitas vezes ocorre de maneira silenciosa e imperceptível, denominada bullying. Com a utilização das tecnologias de informação e comunicação, especialmente a Internet, a violência sem que a vítima tenha capacidade de se defender é chamada de cyberbullying.

Em ambos os casos, as vítimas costumam ser pessoas "diferentes" das demais (peso, estatura, raça, preferências sexuais, entre outros), motivo pelo qual são humilhadas, constrangidas ou excluídas por fatores relacionados à aparência física ou comportamentos apresentados que não se enquadram na padronização e homogeneização social. 
Realizou-se neste estudo, a abordagem da série norte-americana "13 reasons why", comparando-a com a realidade brasileira demonstrada na última "Pesquisa Nacional de Saúde do Escolar", a qual foi aplicada em 2015, pelo Instituto Brasileiro de Geografia e Estatística. Nos dois contextos resta evidenciada a prática de violência envolvendo jovens, o que ratifica a necessidade de enfrentamento do tema em âmbito científico.

Como visto, normalmente, a violência revela-se como uma intolerância capaz de atingir a honra, imagem e, sobretudo, dignidade do ofendido, violando direitos fundamentais constitucionalmente protegidos, o que revela a ilicitude do bullying e do cyberbullying.

Seguindo o disposto na Constituição Federal, a escola deveria promover um ambiente socializador em que crianças e adolescentes aprendam a conviver de forma harmônica e democrática. Contudo, sob a guarda e vigilância da instituição, alguns alunos, infelizmente, utilizam a violência contra colegas mais fragilizados em seus aspectos físico, psíquico e social.

Deste modo, verificou-se que, além da possibilidade de responsabilização do(s) agressor(es), a escola também é civilmente responsável em casos de violação de direitos fundamentais em razão da prática de bullying ou cyberbullying, com base no ordenamento jurídico brasileiro e no entendimento dos Tribunais, ambos analisados no presente estudo.

Ademais, em face da essencialidade de que se discuta e que se evite essas práticas de violência, foi promulgada lei nacional (Lei n 13.185, de 06 de novembro de 2015), que instituiu o Programa de Combate à Intimidação Sistemática (bullying), em todo o Território Nacional, a fim de disseminar o combate e a prevenção do bullying.

Todavia, para que tais políticas sejam possíveis e eficazes, é importante que haja a qualificação e preparo dos professores e demais colaboradores para solucionar com o problema, além de uma efetiva cooperação social. A colaboração inicia com a denúncia de situações de violência pelas pessoas envolvidas, sobretudo testemunhas de violação de direitos.

Nesse diapasão, deve ser fomentado, ainda, o respeito às diferenças, bem como disseminados esclarecimentos acerca dos fenômenos ora discutidos (bullying ou cyberbullying), amenizando assim os conflitos estudantis, bem como as graves consequências que podem ocorrer se não houver assistência para a(s) vítima(s).

Nesta senda, é de suma importância que a sociedade e principalmente, as escolas, exerçam uma postura ativa quanto ao combate à proliferação da violência, de modo que esta seja cada vez mais debatida e legislada adequadamente. Isso, pois, o bullying normalmente inicia na escola e se estende para o ciberespaço (cyberbullying). 
Diante dessas reflexões, o estudo proporcionou a constatação de que a busca por um ambiente escolar e virtual sadio e seguro, é um desafio que está posto, merecendo o tema ora abordado a devida reflexão e análise, diante de sua gravidade e recorrência. É essencial a prevenção de toda e qualquer violência que implique em violação de direitos fundamentais, a qual deve ser realizada de acordo com o disposto na recente e inovadora Lei $n^{\circ} 13.185$, de 06 de novembro de 2015.

\section{REFERÊNCIAS}

ASSOCIAÇÃO BRASILEIRA MULTIPROFISSIONAL DE PROTEÇÃO À INFÂNCIA E À ADOLESCÊNCIA - ABRAPIA. Programa de redução do comportamento agressivo entre estudantes. Disponível em: <http://www.observatoriodainfancia.com.br/IMG/pdf/doc154.pdf>. Acesso em: 15 ago. 2018.

BARBOSA, Carlos Cezar. Responsabilidade civil do Estado e das instituições privadas nas relações de ensino. Rio de Janeiro: Forense Universitária, 2004.

BARUFFI, Helder. Direitos Fundamentais e cidadania. Coordenado por Zulmar Fachin, Editora Método, São Paulo, 2008.

BEANE, Allan L., 1950. Proteja seu filho do bullying. Traduzido por Débora Guimarães Isidoro. Rio de Janeiro: BestSeller, 2010.

BRASIL. Conselho Nacional de Justiça. Cartilha 2010 - Projeto Justiça nas Escolas. 1. ed. Autora: Ana Beatriz Barbosa Silva. Brasília: 2010.

Constituição da República Federativa do Brasil. Diário Oficial da República Federativa do Brasil, Brasília, DF, 05 de outubro de 1988. Disponível em: <http://www.planalto.gov.br/ccivil_03/constituicao/constitui\%C3\%A7ao.htm>. Acesso em: 15 ago. 2018.

Lei $\mathrm{n}^{\circ}$ 8.069, Estatuto da Criança e do Adolescente. Diário Oficial da República Federativa do Brasil, Brasília, DF, 13 de julho de 1890. Disponível em: <http://www.planalto.gov.br/ccivil_03/Leis/L8069.htm>. Acesso em: 15 ago. 2018.

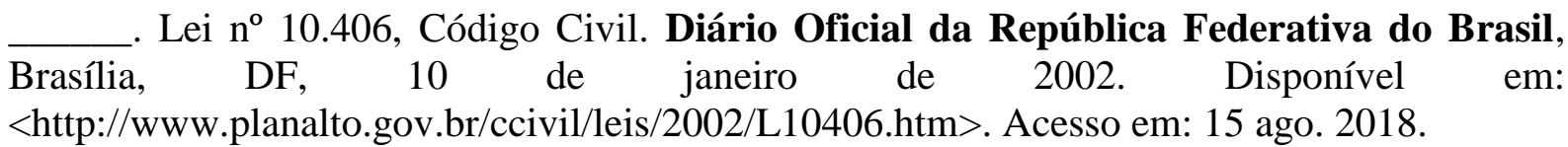

Bullying Escolar no Brasil - Relatório Final. São Paulo: CEATS/FIA, 2010.

CALHAU, Lélio Braga. Bullying: o que você precisa saber. Identificação, prevenção e repressão. Niterói, RJ: Impetus, 2009. 
CARVALHO, Renato Gil Gomes. Isolamento social nas crianças: propostas de intervenção cognitivo-comportamental. Revista Iberoamericana de Educación. n. 40/3. Organización de Estados Iberoamericanos para la Educación, la Ciencia y la Cultura (OEI), 2006. Disponível em: 〈http://www.rieoei.org/deloslectores/1435Gil.pdf>. Acesso em: 15 ago. 2018.

CAVALIERI FILHO, Sergio. Programa de responsabilidade civil. 9. ed. São Paulo: Atlas, 2010.

CONSTANTINI, Alessandro. Bullying, como combatê-lo?: prevenir e enfrentar a violência entre jovens. São Paulo: Itália Nova editora, 2004.

FANTE, Cleo. Fenômeno "bullying": como prevenir a violência nas escolas e educar para a paz. 2. ed. ver. e ampl. Campinas: Verus, 2005.

FERRAZ, Sérgio. Manipulações biológicas e princípios constitucionais: uma introdução. Porto Alegre: S. A. Fabris, 1991.

GOMES, Marcelo Magalhães. O bullying e a responsabilidade civil do estabelecimento de ensino privado. Jus Navigandi, Teresina, ano 16, n. 2844, 15 abr. 2011. Disponível em: <https://jus.com.br/artigos/18907/o-bullying-e-a-responsabilidade-civil-do-estabelecimentode-ensino-privado>. Acesso em: 15 ago. 2018.

GUARESCHI, Pedrinho Guareschi; SILVA, Michele Reis da. Bullying mais sério do que se imagina. Porto Alegre: EDIPUCRS, 2008.

HIRIGOYEN, Marie-France. Mal-Estar no Trabalho: redefinindo o assédio moral. Traduzido por Rejane Janowitzer. Rio de Janeiro: Bertrand Brasil, 2002.

LEVY, Pierre. Cibercultura. São Paulo: Editora 34 Ltda, 1999.

MARQUES, Cláudia Lima. Comentários ao Código de Defesa do Consumidor. São Paulo: Revista dos Tribunais, 2003.

NETO, Aramis Antonio Lopes. Bullying: comportamento agressivo entre estudantes. Jornal de Pediatria, Vol. 81, n. 5(supl), 2005.

PEREIRA, Beatriz Oliveira. Para uma Escola sem violência: estudo e prevenção das práticas agressivas entre crianças. Porto: Fundação Calouste Gulbenkian, 2002.

SHARIFF, Shaheen. Ciberbullying: questões e soluções para a escola, a sala de aula e a família. Traduzido por Joice Elias Costa. Revisado por Cléo Fante. Porto Alegre: Artmed, 2011.

SILVA, Ana Beatriz Barbosa. Bullying: mentes perigosas na escola. Rio de Janeiro: Objetiva, 2010.

STOCO, Rui. Responsabilidade Civil e sua Interpretação Jurisprudência. São Paulo: Revista dos Tribunais, 1999. 